\title{
A Description of the English Non-finite Verbal Group Clause
}

\author{
Roseline Abonego Adejare ${ }^{1}$ \\ ${ }^{1}$ Department of Language, Arts and Social Science Education, Lagos State University, Ojo, Lagos, Nigeria \\ Correspondence: Roseline Abonego Adejare, Department of Language, Arts and Social Science Education, Lagos \\ State University, Ojo, Lagos, Nigeria
}

Received: April 2, 2015

Accepted: April 16, 2016

Online Published: April 19, 2016

doi:10.5430/elr.v5n2p1

URL: http://dx.doi.org/10.5430/elr.v5n2p1

\begin{abstract}
Existing studies of the English non-finite verbal group (VBG) clause are lopsidedly semantic descriptions with focus on $t o-\mathrm{x}+\mathrm{o}$ and $\mathrm{x}+\mathrm{g}$ forms only. This paper exhaustively describes the English non-finite VBG clause, determines its frequency of occurrence, identifies its functional and positional distribution, and accounts for variations in its syntactic behaviour. Analysed using the systemic grammatical model, the data comprises 643 non-finite VBG clauses obtained from an 18000 -word corpus of five written texts. Results reveal a frequency of occurrence of 36 in 1000 words that ranged between 46.3 and 31.7 in the individual texts. The to-x+o form was the most frequent, followed by $\mathrm{x}+\mathrm{g}, \mathrm{x}+\mathrm{n}$ and $\mathrm{x}+\mathrm{o}$. Respectively they featured $17,11.3,7$ and 1.33 times in 1000 words and represent 46, 32, 18 and 4 percent of the data. The non-finite VBG clause's most prominent syntactic position was adjunct, where its 35 percent realisation was about $2^{1 / 2}$ times more than its function as beta clause, nominal group qualifier, and prepositional group qualifier. While its realisation as catenated VBG headword was 0.93 percent and qualifier 16.2 percent, its proportion as adjectival group qualifier, subject and complement was $0.16,0.31$ and 5 percent respectively. Features inherent in the non-finite VBG clause, authors' individualism, and theses variation explain the differences.
\end{abstract}

Keywords: Non-finite verbal group, Non-finite verbal group clause, Verb morphology, Verb syntax

\section{Introduction}

\subsection{Background}

One of the several systems that converge on the English verbal group (VBG) is finiteness, with finite and non-finite as terms. A verb is finite if it makes tense, mood, person or number contrast; otherwise, it is non-finite. A VBG headed by a finite verb, or initiated by a finite auxiliary verb, is called a finite VBG and the clause in which it functions as predicator is known as a finite VBG clause. In contrast, a non-finite verb heads the non-finite VBG, which initiates the non-finite VBG clause (Berry, 1975; Eggins,2004;Palmer,1987; Scott et al.,1968). This study is concerned with the non-finite VBG clause. Being the marked term in the system of finiteness (Strang, 1969) makes the non-finite VBG and the clause it initiates descriptively more compelling and challenging.

Although the non-finite VBG clause has been extensively described, a number of problems remain (Huddleston, 1984) even today. First, it has been established to also function as an element of sentence, clause and group structure (Kolln \& Funk, 2010) but there is no comprehensive quantitative assessment of its occurrence in these syntactic positions known to the present writer. Second, what exists as proportion of its morphological variants in texts is essentially on to-infinitive and -ing; the bare infinitive and past participle variants hardly attract a mention. Third, there is confusion over the syntactic status of the non-finite VBG immediately following the catenative verb: Is it an element of the catenated VBG structure or an element of clause structure? Forms in this category incidentally constitute the bulk of studies in the fast-evolving field verbal complementation (cf. Deshors, 2015; De Smet, 2007; Egan, 2008; Farego, 1997), leading to the erroneous perception that the non-finite form occurs exclusively with catenatives. Since non-finite VBG clauses indeed realise elements of structure of syntactic units, it is only appropriate to account for all accordingly.

In the light of the foregoing, this paper exhaustively describes the English non-finite VBG clause. It determines its frequency of occurrence, identifies its functional and positional distribution in the structure of the grammatical units within which it operates, and accounts for variations in its syntactic behaviour in terms of morphological shapes and functions. The paper thus provides answers to the following questions: How frequently does the non-finite VBG 
clause occur? Which form(s) occur(s) in given syntactic positions and why? Do thesis variation and authorial style influence its pattern of occurrence? It is therefore neither concerned with meaning in the non-finite VBG clause nor with related features of nominalisation and adjectivisation as in Alexiadou (2013) and Taher (2015).

\subsection{Studies on the Non-finite Verbal Group Clause}

To fully appreciate the need for the current study it is pertinent to examine the scope of work done so far on the non-finite VBG clause. Rodhenberg (1995) investigates diachronically the syntactic contrasts between complements realised by finite clauses with explicit subjects and those realised by infinitive clauses lacking a subject and the principles accounting for the relationship. Farego (1997) studies verbs of effort diachronically and synchronically, focusing on the meaning of try when followed by to-infinitive. Rudanko (1998) focuses on matrix verbs that potentially change their complementation type from to-infinitive to to-ing between two distinct periods. Duffley (2004) examines and accounts for the differences between to-infinitive and gerund when they occur with verbs of liking. De Smet (2007) describes present-day distribution of for...to-infinitive as verbal complement and its diachronic process of gradual diffusion. Duffley and Tremblay (2008) investigate the use of the infinitive and -ing with the verb of effort try. Egan (2008) determines the type of infinitive and -ing complement constructions that occur in present-day British English, their frequency of occurrence, and the motivation behind their choices. Finally, Deshors (2015) investigates the extent to which the lexico-semantic environment of gerundial and to-infinitival constructions differ in native and ESL varieties.

What most strikingly emerges from these highlights is that the non-finite VBG clause is not a green field research-wise but efforts have been lopsided in many respects. First, none of the studies covers all the four morphological variants: They are limited to to-infinitive and -ing as already indicated above (Egan pays some attention to the bare infinitive, though). Second, existing studies are exclusively semantic in approach as Deshors (2015) points out, and some are restricted to complementation of specific verb categories such as verbs of effort and verbs of liking. Third, they utilise large corpora and many are either diachronic or contrastive. Fourth, all are moreover comparative and statistics-oriented: They compare the complementation patterns of to-infinitive and -ing and determine their distribution when only a semantic category is focused upon, undermining critical grammatical features of the forms in the process. Lastly, even though the works concern themselves with frequency distribution, this is limited to their roles as verbal complements and does not extend to other known syntactic functions such as subject. For instance, although Egan (2008) notes that the to-infinitive may also function adverbially and as subject, evidence about its relative frequency was restricted to its collocation with four matrix verbs (live, love, win and write). These gaps further justify the current study.

\subsection{Descriptive Perspectives on the Non-finite Verbal Group Clause}

This review of existing description of the non-finite VBG clause aimed at resolving some of the contentious issues and determining an appropriate descriptive framework to adopt covers its morphology, syntactic functions, frequency of occurrence, and descriptive problems.

Five forms of the English verb are generally recognised in the grammar, namely base form, $-s$ form, -ing participle form, -ed past form, and -ed/-en past participle form (Jespersen, 1933; Palmer, 1987; Quirk et al., 1985). For mnemonics, $\mathrm{x}+\mathrm{o}, \mathrm{x}+\mathrm{s}, \mathrm{x}+\mathrm{g}, \mathrm{x}+\mathrm{d}$, and $\mathrm{x}+\mathrm{n}$ are respectively used, where $x$ stands for the verb lexeme and others represent absence $(o)$ or presence of a given inflection (Adejare \& Adejare, 2006). The $\mathrm{x}+\mathrm{s}$ and $\mathrm{x}+\mathrm{d}$ forms are inherently finite while $x+g$ and $x+n$ are intrinsically non-finite. The $x+o$ form however maintains a dual status: Its finite variant has all the features associated with finite, including imperative mood marking. Its non-finite variant is further distinguished according to whether it occurs with, or, without, preposition to. These are traditionally called to-infinitive and bare/plain infinitive respectively. According to Strang (1969), the to-infinitive is "regarded as the normal infinitive, in the sense that it is the form used in infinitive position unless there is a positive reason for using the plain infinitive" (p.170). The particle to is likened to the auxiliary syntactically (Radford,2004). The bare infinitive combines with modal auxiliaries to produce finite VBGs, or occurs alone as head of its own non-finite VBG. There are thus four non-finite VBG forms, namely $\mathrm{x}+\mathrm{o}$, to $-\mathrm{x}+\mathrm{o}, \mathrm{x}+\mathrm{g}$, and $\mathrm{x}+\mathrm{n}$ (Downing \& Locke, 2002; Huddleston, 1984; Palmer, 1987; Quirk et al.,1985; Strang,1969). Greenbaum and Nelson (2002) do not however acknowledge $x+o$ as one and so recognise three instead. For us, we shall work with the proposition that there exits four non-finite VBG forms and therefore four morphological variants of the non-finite VBG clause.

The syntactic functions associated with the non-finite VBG clause (cf. Downing \& Locke, 2002; Palmer, 1987; Quirk et al., 1985; Strang,1969) are as tabulated below. 
Table 1. Syntactic Functions of the Non-finite Verbal Group Clause

\begin{tabular}{lcccc}
\hline Functions & \multicolumn{4}{c}{ Forms } \\
\hline Beta Clause & $\mathrm{x}+\mathrm{o}$ & to $-\mathrm{x}+\mathrm{o}$ & $\mathrm{x}+\mathrm{g}$ & $\mathrm{x}+\mathrm{n}$ \\
Subject & $\mathrm{x}+\mathrm{o}$ & to $-\mathrm{x}+\mathrm{o}$ & $\mathrm{x}+\mathrm{g}$ & $\mathrm{x}+\mathrm{n}$ \\
Complement & $\mathrm{x}+\mathrm{o}$ & to $-\mathrm{x}+\mathrm{o}$ & $\mathrm{x}+\mathrm{g}$ & $\mathrm{x}+\mathrm{n}$ \\
Adjunct & $\mathrm{x}+\mathrm{o}$ & to $-\mathrm{x}+\mathrm{o}$ & $\mathrm{x}+\mathrm{g}$ & $\mathrm{x}+\mathrm{n}$ \\
NMG Qualifier & & $t o-\mathrm{x}+\mathrm{o}$ & $\mathrm{x}+\mathrm{g}$ & $\mathrm{x}+\mathrm{n}$ \\
PRG Qualifier & $\mathrm{x}+\mathrm{o}$ & & $\mathrm{x}+\mathrm{g}$ & \\
AJG Qualifier & & & $\mathrm{x}+\mathrm{g}$ & \\
ADG Qualifier & & & $\mathrm{x}+\mathrm{g}$ & \\
Catenated VBG Qualifier & $\mathrm{x}+\mathrm{o}$ & to $-\mathrm{x}+\mathrm{o}$ & $\mathrm{x}+\mathrm{g}$ & $\mathrm{x}+\mathrm{n}$
\end{tabular}

Table 1 shows that the non-finite VBG clause operates at three different syntactic depths: It operates at the primary degree of delicacy (i.e. as an optional element of sentence structure - dependent beta clause), secondary degree of delicacy (i.e. as an element of clause structure - subject, complement and adjunct), and tertiary degree of delicacy (i.e. as an element of group structure-qualifier in the nominal group (NMG), adjectival group (AJG), adverbial group (ADG), prepositional group (PRG), and catenated VBG)). All its morphological variants realise beta clauses, subjects, complements, adjuncts, and qualifiers (the catenated VBG only) and, while $x+g$ occurs in all positions, $x+n$ and $t o-x+o$ do not function as qualifier in the PRG structure. The $x+o$ non-finite VBG clause similarly does not function as qualifier in the NMG structure. It however occurs as PRG qualifier after prepositions of exception only, such as but in Quirk et al.'s (1985) "She did everything but make her bed" (p.1 067), and as subject in "equative Wh-cleft sentences" (p.34), as Downing and Locke (2002) note. Probably because of the limited currency of $x+o$ (Scott et al.,1968), Greenbaum (1996) asserts that $\mathrm{x}+\mathrm{g}$ "is the only verb form possible in a non-finite clause functioning" (p.278) as qualifier in the PRG structure.

Reports concerning the frequency of the non-finite VBG clause are characterised by in-exactitudes and contradictions. Scott et al. (1968) state that $t o-x+0$ and $x+g$ are the highest occurring forms without empirical evidence. Huddleston (1984) similarly asserts that $t o-x+o$ and $x+g$ occur with a significant number of catenatives but leaves out their frequency. In their report on the relative frequency of seven structures that realise the adverbial, Quirk et al. (1985) lump the non-finite VBG clause together with the verbless clause. Their statement that the $x+g$ clause is "the numerically strongest subtype" (p.490) contradicts Kolln and Funk's (2010) claim that to-x+o is the most common as adverbial. Though Farrokh and Mahmoodzadeh (2012) identify the most frequent $w h$-word used in subordinate clauses involving both $\underline{w h}$-words and infinitive constructions, they neither determine the frequency of the infinitive constructions themselves nor separate $w h$-clauses without infinitives from those with infinitives. Egan (2008) gives projected frequency of the complement constructions studied relative to the 310 matrix verbs used rather than their exact frequency in the corpus.

Some studies however provide statistical evidence to support the claim that to- $x+0$ occurs with a far greater frequency than $\mathrm{x}+\mathrm{g}$ even with specific verb categories. Deshors' (2015) study show 86 and 14 percent in favour of to- $\mathrm{x}+\mathrm{o}$ construction while Duffley (2004) reports a disparity of 93 and 7 percent for $t o-\mathrm{x}+\mathrm{o}$ and $\mathrm{x}+\mathrm{g}$ in respect of like (Author's percentages). On the relative frequency of $t o-x+o$ and $x+g$ as qualifiers in the catenated VBG structure, Adejare (2013) finds a ratio of 14:5 in favour of $t o-\mathrm{X}+\mathrm{o}$. With respect to for...to-infinitive as verbal complements De Smet (2007) reports a frequency of 50 in 1000,000 (i.e. 0.05 in 1 000) words.

Two major descriptive problems are associated with the to-non-finite VBG. The first relates to the semi auxiliary verb (e.g., BE ABLE TO) sometimes classified as non-finite (Strang, 1969) due probably to its to ending. This multi-word item is non-finite only if its initiating lexical BE or HAVE is morphologically non-finite. In that case, it may be preceded by a modal, such as in may be able to assign (N23) in our data base; initiate a non-finite VBG clause, such as in $\|(\beta)$ Being unable to supervise the project $\|$; or co-occur, where the one is finite, and the other(s) non-finite, as in Quirk et al.'s (1985) "The students are going to have to be able to play three different instruments"(p.237). The second descriptive problem relates to the syntactic status of the non-finite form immediately following the catenative verb pointed out above. It is sometimes excised from the catenated VBG structure, as Huddleston (1984) does in, for example, "[Ed hoped] to repair it" (p.210). As will be further 
demonstrated below, forms like to repair are qualifiers and do not initiate clauses in complement or adjunct position (cf. Adejare, 2013; Downing \& Locke, 2002).

\section{Methodology}

\subsection{Data Sources}

This study's data base comprises five written texts entitled "El-Rufai and his Beggars", The 48 Laws of Power, Merchant Prince of the Niger Delta, Who Needs Parents?, and The Politics of Bones. Abbreviated B,L,M,N and P respectively for easy in-text referencing, all are books except Text B. The authors, who minimally hold the bachelor's degree, comprise a journalist and columnist with Nigeria's widest selling newspaper who is also a doctoral student and teacher at the University of Texas (Text B), a journalist, playwright and erstwhile magazine editor (Text L), a retired professor of History (Text M), a sociologist and Senior Research Fellow in the family (Text $\mathrm{N}$ ), and an award-winning Toronto journalist (Text P). The texts deal with different theses, namely beggars (Text B), power (Text L), history (Text M), childcare (Text N), and biography and politics (Text P). This combination of individual expertise and varieties of theses represents World Standard English usage.

Since using each book's entire contents would yield data most unwieldy, only the initial chapters (except for Text P) were selected. A manual word count was undertaken to determine the corpus size. Respectively Texts B,L,M,N and P generated 1 081, 2 678, 8 454, 2 556, and 3185 words. These total 17 954, which is approximately 18000 words.

Some clarifications on the sources of data and size of corpus are necessary at this point. A recent personal experience had led me to consult Text N, where I was first struck by high non-finite VBG occurrence and related syntactic features. That propelled me to reread the others, after which I became convinced of the viability of the non-finite VBG clause as a subject and the adequacy of the texts as data sources. The decision to add Text B was irresistibly spontaneous: I had already begun preliminary examination of the earlier texts when, as I read my favourite Thursday column in The Punch of 16 July 2015, my linguistic instinct again caused me to notice the non-finite VBG. As the analysis would reveal shortly, tailor-made corpora are not the only authentic samples of natural language. Besides, I am not comparing varieties or periods or authors; I am just interested in describing my subject as encountered in texts. A corpus size of approximately 18000 words might be deemed small, given that most studies' corpora run into a million or more words. But a corpus or sample needs not be large to serve its intended purpose. The paradox, as Ihalainen (2004) most succinctly puts it, is that "in some cases a relatively small sample may help us see trends that a much larger sample might obscure" (p.117). For this study's motivating factors and goals the sources of data and size of corpus are considered adequate.

\subsection{Analytical Framework}

The systemic grammatical model (Berry, 1975; Halliday,1961) is the analytical framework chosen because the study is grammatical (not semantic) and the data is actual (not introspective). A sociologically-based model, systemic grammar has the proven capacity to efficaciously handle units of language below the sentence through its four descriptive categories (class, unit, structure and system), five units (sentence, clause, group, word and morpheme) and three scales of abstraction (exponence, rank and delicacy). It would therefore be possible to identify and account for every occurring non-finite VBG clause in the corpus. Some statistics in the form of simple percentages complement the analysis.

\subsection{Analytical Procedure}

Each text was first examined to identify all the non-finite VBG clause-bearing sentences. These were copied out, with the non-finite VBG clauses marked. Next, the sentences were analysed into their elements of structure to identify the functional position of every non-finite VBG clause therein. Lastly, all the non-finite VBGs were listed in a tabular form in accordance with their identified functions and positions. In other words, they were tabulated according to whether their clauses realised an element of structure of the sentence (beta clause), clause (subject, complement, or adjunct), or group (NMG, PRG, AJG, catenated VBG qualifier or headword). This was done for every form and for every syntactic position and the total was determined. Texts B,L,M,N and P yielded 50, 112, 131, 269 , and 81 non-finite VBG clauses respectively. This gives 643 , which constitutes the data analysed and presented in two parts as follows.

\section{Frequency of Occurrence and Distribution within Syntactic Units}

\subsection{Frequency of Occurrence}

Mindful of significant variations in the size of each text and the need to objectively determine the frequency of the non-finite VBG clause, occurrence in 1000 words was used as criterion. This reveals an average of 36 in 1000 
words. The frequency of occurrence however varied markedly according to texts: It was 46.3 non-finite VBG clauses in 1000 words in Text B; 41.8 in 1000 in Text L; 31.8 in 1000 in Text M; 31.7 in 1000 in Text N, and 41.13 in 1 000 in Text P. The non-finite VBG clause was thus least frequent in Text $\mathrm{N}$ and most frequent in Text B. With respect to the forms the rate was 17 in 1000 words for $t o-\mathrm{x}+\mathrm{o}, 11.3$ in 1000 for $\mathrm{x}+\mathrm{g}, 7$ in 1000 for $\mathrm{x}+\mathrm{n}$, and 1.33 in 1000 for $\mathrm{x}+\mathrm{o}$. The $\mathrm{x}+\mathrm{g}$ form was highest in Text $\mathrm{L}(18.3$ in 1000$)$ and lowest in Text $\mathrm{M}(8.4$ in 1000$)$. While $t o-\mathrm{x}+\mathrm{O}$ was most frequent in Text $\mathrm{P}$ (21.4in 1000$)$ and least frequent in Text $\mathrm{N}(13.3$ in 1000$)$, $\mathrm{x}+\mathrm{n}$ was most frequent in Text B (10.2 in 1000$)$ and least frequent in Text P(4.4 in 1 000). Finally, $x+o$ was highest in Text L (4.9 in 1000$)$ and lowest in Text M (0.12 in 1000$)$. These facts and figures are exposed in Table 2 below.

Table 2. Frequency of the Non-finite Verbal Group Clause

\begin{tabular}{|c|c|c|c|c|c|c|}
\hline & Text B & Text L & Text M & Text $\mathrm{N}$ & Text P & Total \\
\hline Size & 1081 & 2678 & 8454 & 2556 & 3185 & 17954 \\
\hline Form & & & & & & $\cong 18000$ \\
\hline to $-\mathrm{x}+\mathrm{O}$ & 22 & 37 & 136 & 34 & 68 & 297 \\
\hline Frequency & 20.4 & 14 & 16.1 & 13.3 & 21.4 & 17 \\
\hline$x+g$ & 14 & 49 & 71 & 26 & 43 & 203 \\
\hline Frequency & 13 & 18.3 & 8.4 & 10.2 & 14 & 11.3 \\
\hline$x+n$ & 11 & 13 & 61 & 20 & 14 & 119 \\
\hline Frequency & 10.2 & 4.9 & 7.2 & 7.8 & 4.4 & 7 \\
\hline$x+0$ & 3 & 13 & 1 & 1 & 6 & 24 \\
\hline Frequency & 2.8 & 4.9 & 0.12 & 0.4 & 1.9 & 1.33 \\
\hline TOTAL & 50 & 112 & 269 & 81 & 131 & 643 \\
\hline Frequency & 46.3 & 41.8 & 31.8 & 31.7 & 41.13 & 36 \\
\hline
\end{tabular}

\subsection{Distribution within Syntactic Units}

Of the 643 non-finite VBG clauses that constitute the data, the to-x+o subtype recurred the most as already seen. It accounted for 46 percent with 297 occurrences and was followed by $x+g$ with 32 percent (203), $x+n$ with 19 percent (119), and $x+o$ with 4 percent (24) in that order. Fourteen percent (90) of the non-finite VBG clause realised an element of sentence structure, 40 percent (259) realised an element of clause structure, and 46 percent (294) realised an element of group structure. Table 3 below displays the functional and positional distribution of the non-finite VBG clause and its morphological variants. The symbol $(\beta)$ stands for beta clause; [[S]], [[C]], and [[A]] stand respectively for rankshifted clause as subject, complement, and adjunct; [[Q]]NMG, [[Q]]PRG, and [[Q]]AJG represent rankshifted clause as qualifier in the NMG, PRG, and AJG structure respectively; and C-Q and C-H stand respectively for catenated VBG qualifier and headword.

Table 3. Functional and Positional Distribution of the Non-finite Verbal Group Clause

\begin{tabular}{|c|c|c|c|c|c|c|c|c|c|c|c|}
\hline & $(\beta)$ & [[S]] & {$[[\mathrm{C}]]$} & {$[[\mathrm{A}]]$} & [[Q]] & [[Q]] & [[Q]] & C-Q & $\mathrm{C}-\mathrm{H}$ & Total & $\%$ \\
\hline Form & & & & & NMG & PRG & AJG & & & & \\
\hline to $-\mathrm{x}+\mathrm{O}$ & 11 & 0 & 15 & 176 & 3 & 0 & 0 & 92 & 0 & 297 & 46 \\
\hline$x+g$ & 53 & 1 & 8 & 19 & 21 & 89 & 0 & 6 & 6 & 203 & 32 \\
\hline$x+n$ & 26 & 1 & 2 & 16 & 70 & 0 & 1 & 3 & 0 & 119 & 19 \\
\hline$x+o$ & 0 & 0 & 4 & 17 & 0 & 0 & 0 & 3 & 0 & 24 & 4 \\
\hline Total & 90 & 2 & 29 & 228 & 94 & 89 & 1 & 104 & 6 & 643 & \\
\hline$\%$ & 14 & 0.31 & 5 & 35 & 15 & 14 & 0.16 & 16.2 & 0.93 & & \\
\hline
\end{tabular}

Nine functional positions were realised in all. These are adjunct, which accounted for 35 percent, and subject and complement, which represent 0.31 percent and 5 percent respectively. The non-finite VBG clause's realisation as qualifier in the NMG, PRG, and AJG was 15,14 , and 0.16 percent respectively. Its function as beta clause represents 14 percent, while the headword and qualifier elements of the catenated VBG structure accounted respectively for 
0.93 percent and 16.2 percent. The adjunct was thus the most prominent position and the AJG qualifier was the least frequent.

\section{Syntactic Analysis}

In the presentation that follows critical attention is paid to the syntactic behaviour of the non-finite VBG clause. Each morphological variant is accorded a separate heading but their occurrence in the catenated VBG structure is considered together. Analysed examples are provided as appropriate, with the non-finite VBG clause italicised and the non-finite VBG therein marked bold. The source text for each cited example is enclosed in brackets, with its page (paragraph for Text B) number placed in front. Tree diagrams are drawn where necessary.

\subsection{The to- $x+o$ Non-finite Verbal Group Clause}

With 297 occurrences representing 46 percent of the data, the $t o-x+o$ non-finite VBG clause was the most recurring as already stated. Four percent (11) occurred as an element of sentence structure, 64 percent (191) realised an element of clause structure, and 32 percent (95) featured as an element of group structure. These are examined more closely below.

\subsubsection{The $t o-x+o$ Non-finite Verbal Group Clause as an Element of Sentence Structure}

Eleven (4 percent) to-non-finite VBG clauses realised an element of sentence structure as dependent beta clauses. Two are presented in their sentence context and analysed into their elements of structure as follows.

(1a) || ( $\beta$ ) To continue courting Ogoni people under forty, $\|(\alpha)$ Ken organized a two-day tour of all six Ogoni kingdoms in November1992.||| (P67)

$$
\mathrm{P} \quad \mathrm{C} \quad \mathrm{A}
$$

(1b) || ( $\beta$ ) To continue courting |Ogoni people |under forty,\|

(2a) || ( $\beta$ ) To succeed Fouquet, $\|(\alpha)$ Louis chose Jean-Baptiste Colbert, a man famous for his parsimony and for giving the dullest parties in Paris.||| (L2)

$$
\mathrm{P} \quad \mathrm{C}
$$

(2b) \| ( $\beta$ ) To succeed |Fouquet, $\|$

\subsubsection{The $t o-\mathrm{x}+\mathrm{o}$ Non-finite Verbal Group Clause as an Element of Clause Structure}

A total of 202 to-non-finite VBG clauses functioned as an element of clause structure and 92 percent (176) of this occurred as adjuncts. None realised subjects but 8 percent (15) featured as complements. Here are illustrations.
$\mathrm{S}$
$P$
$\mathrm{C}$

(3a) || The consul's primary duty |was | [[to protect the lives and property of British traders in the Niger Delta]].\| (M14)
P- $\quad$ S
$-\mathrm{P}$
$\mathrm{C}$

(3b) || Do| people| choose | [ to be beggars?|| (B11)

The prominence of adjuncts referred to earlier is attributable to the to-x+o non-finite VBG clause which accounted for 77 percent of its realisation. Indeed the $t o-x+o$ non-finite VBG clause's occurrence (176) as adjunct represents 59.3 percent of its total manifestation as a morphological variant. Below are examples. Notice coordination in (4e).
$\mathrm{A}_{1}$
$\mathrm{S}$
$\mathrm{A}_{2}$
$\mathrm{A}_{3}$

(4a) || From Sow Fall's book to Zaria,| the beggars |strike |back |at cosmetic efforts|
$\mathrm{A}_{4}$
$\mathrm{A}_{5}$

[[to improve urban aesthetic]]| by removing them from their spots. $\|(\mathrm{B} 7)$
$\mathrm{S} \quad \mathrm{A}$
$\mathrm{P} \quad \mathrm{C}$
$\mathrm{P}$
C
$+$

(4b) ||| ( $\alpha$ ) He |simply loccupied |its fortress, $\|(\alpha)$ executed| none of its citizens, $\|$ and $\|$
$\mathrm{P}$
$\mathrm{C}$
$\mathrm{A}_{1}$
$\mathrm{A}_{2}$

$(\alpha)$ allowed |Prince Manfredi, eighteen at the time,| [[to remain in his court]],| in complete freedom.||| (L5)
$\mathrm{S}$
$\mathrm{P}$
$\mathrm{C}$
$\mathrm{A}_{1}$
$\mathrm{A}_{2}$

(4c) || Their location by the sea |enabled| them | [[to develop into middle men traders |at an early date]].|| (M2) 
$\mathrm{S} \quad \mathrm{P} \quad \mathrm{A}$

(4d) || Childcare | is not| only |a very emotionally, politically and ideologically charged
$\begin{array}{lll}\mathrm{S} & \mathrm{P} & \mathrm{A}_{1}\end{array}$
$\mathrm{C}$
$\mathrm{A}_{2}$

subject, || it | is | also| notoriously difficult |to investigate. ||| (N23)
$\mathrm{A}_{1}$
$\mathrm{S} \quad \mathrm{P}$
$\mathrm{C}$
$\mathrm{A}_{2}$
$\mathrm{A}_{3}$

(4e) || Within two weeks,| Owens| earned |enough money | [[to pay Zor her full wages |and| [[to pay back his uncle]].|| (P61)

\subsubsection{The to-x+o Non-finite Verbal Group Clause as an Element of Group Structure}

As an element of group structure the to-non-finite VBG clause occurred 95 times as NMG (3) and as catenated VBG (92) qualifier only. One NMG with to-non-finite VBG clause as qualifier is analysed as (5a); another is identified in its clause context as (5b); and the third is diagrammed as (5c) to demonstrate its depth of occurrence.

$$
\begin{array}{lll}
\mathrm{M} & \mathrm{H} & [\mathrm{Q}]]
\end{array}
$$

(5a) |any attempt [[to impress him with your grace and generosity]]| (L6)

(5b) || His proposal to create an Ogoni Bill of Rights |was |enthusiastically received.|| (P63)

$(5 \mathrm{c})$

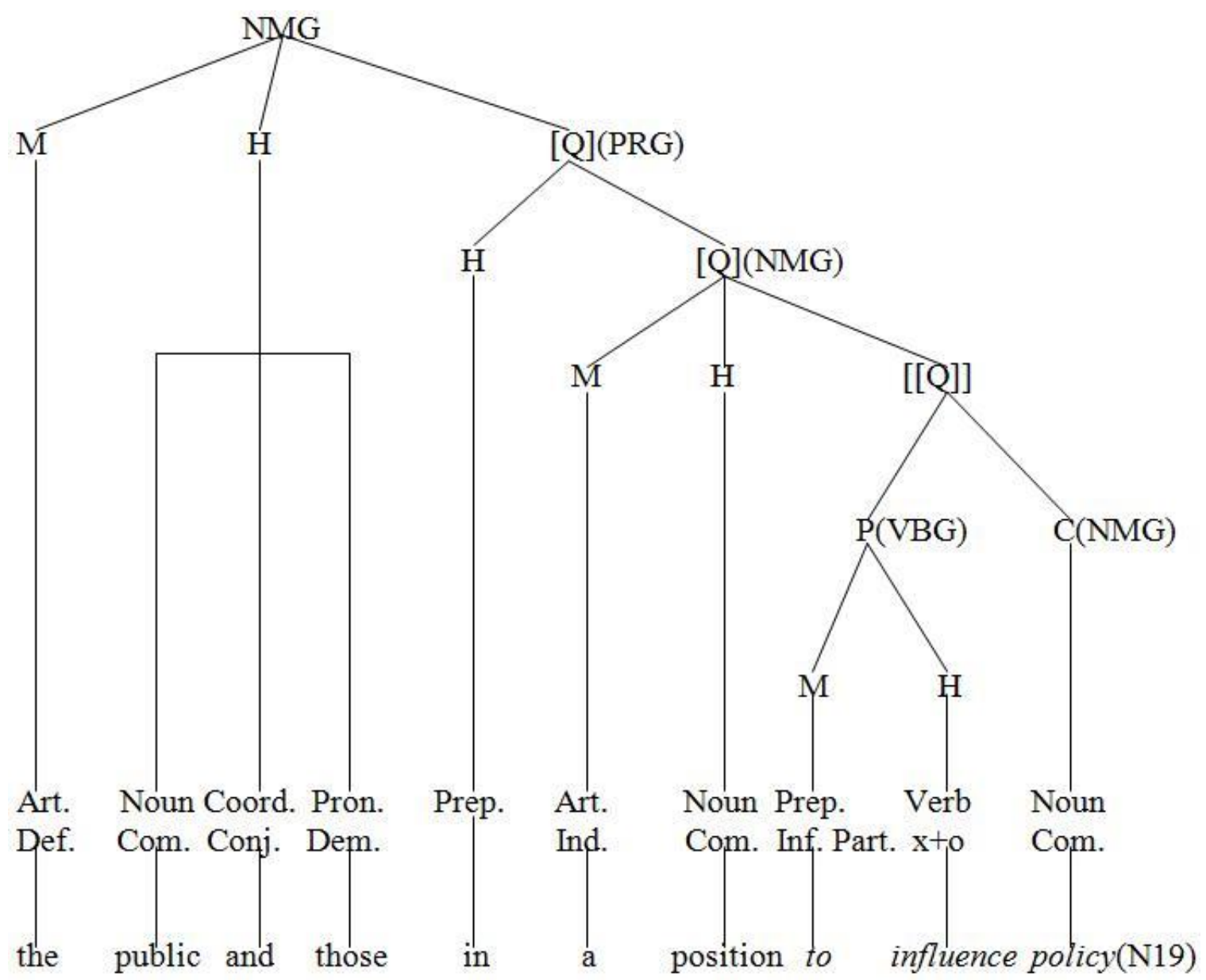

\subsection{The $x+g$ Non-finite Verbal Group Clause}

With 203 occurrences the $\mathrm{x}+\mathrm{g}$ non-finite VBG clause accounted for 32 percent of the data. It featured 53 times as an element of sentence structure, 28 times as an element of clause structure and 122 times as an element of group structure. These respectively represent 26,14 and 60 percent of its total occurrence. 
4.2.1 The $\mathrm{x}+\mathrm{g}$ Non-finite Verbal Group Clause as an Element of Sentence Structure

The $53 \mathrm{x}+\mathrm{g}$ non-finite VBG clauses represent 59 percent of total beta clause occurrence. They featured at initial and end positions as the pairs of sentences below respectively show.

(6a) ||| ( $\beta$ ) Having failed to get | an Olu |elected, $\|(\alpha)$ Beecroft got the Itsekiri to appoint a

Governor of the River.|| (M16)

(6b) ||| ( $\beta$ ) Knowing |the dangers of $[[$ outshining your master $]], \|(\alpha)$ you can turn this law to your advantage. || (L6)

(7a) ||| ( $\alpha$ ) The Itsekiri have never been farmers to any great extent, $\|(\beta)$ their land |being| little suited |to agriculture.||| (M2)

(7b) ||| ( $\alpha$ ) At all hours of the day and night people came to his house, $\|(\beta)$ begging $\mid$ for treatment.||| (P60)

The $\mathrm{x}+\mathrm{g}$ non-finite VBG clause disrupted the structural continuity of the alpha clause.

(8a) || $\mid(\alpha-)$ The beggars, $\|(\beta)$ seeing |their existence threatened, $\|(-\alpha)$ decided to vacate the city.||| (B5)

(8b) || ( $\alpha-)$ His agent, $\|(\beta)$ fearing |[[that the threat might be executed $]], \|(-\alpha)$ applied to Governor Idiare for protection]].|| (M21)

\subsubsection{The $\mathrm{x}+\mathrm{g}$ Non-finite Verbal Group Clause as an Element of Clause Structure}

Twenty-eight $x+g$ non-finite VBG clauses were rankshifted to function as subject (1), complement (8), and adjunct (19) in the number of times indicated in brackets. Here is its single occurrence as subject.
$\ell \quad S \quad P$
A
$\mathrm{S}$
P A
$\mathrm{C}$

(9) ||| ( $\beta$ ) When| it |comes |to power,|| ( $\alpha$ ) [[outshining the master]] |is| perhaps | the worst mistake of all.||| (L4)

The complements either occurred singly in declarative and imperative clauses or were coordinated. Excerpts (10a) (10c) respectively illustrate.
$\mathrm{S}$
$\mathrm{P}$
$\mathrm{C}$

(10a) || He| could not countenance | [[being outdone in lavishness by anyone]].|| (L2)
$\mathrm{P}$
$\mathrm{C}$
$\mathrm{P}$
$\mathrm{C}$

(10b) || Avoid| [[outshining the master]] ||...|| Do not risk| [[outshining feeble superior ]].|| (L7)

(10c) || This staple move of those who wish to exonerate something in the face of adverse

$$
\begin{array}{llll}
\mathrm{P} & \mathrm{C}_{1}+\mathrm{C}_{2}
\end{array}
$$

associations| involves | [[dispersing ]] |or|| [[dismembering its components]].|| (N22)

Two-thirds of $\mathrm{x}+\mathrm{g}$ realisation as an element of clause structure were as adjuncts; $1 / 3$ of this occurred in Text $\mathrm{N}$.

$$
\begin{array}{lllllll}
\mathrm{S} & \mathrm{P}- & \mathrm{A}_{1} & -\mathrm{P} & \mathrm{C} & \mathrm{A}_{2} & \mathrm{~A}_{3}
\end{array}
$$

(11a) || His mother| could |hardly |take |a step | without him | [ running after her in a panic $]] \mid . .$.
$\mathrm{A}_{1}$
S P
$\mathrm{C}_{1}$
$\mathrm{A}_{2}$
$\mathrm{A}_{3}$

|| In the afternoon| we |would find| him |[[sitting in a row of high chairs]],| like an orphan,
$\mathrm{A}_{4}$
$\mathrm{A}_{5}$
$\mathrm{C}_{2}+\mathrm{C}_{3} \mathrm{C}_{4}+$
$\mathrm{C}_{5}$

|[[waiting to be fed,]] |or| [[lying in his cot]],|awake |but |silent,| dazed | and |almost catatonic.|| (N20)
$\mathrm{S} \quad \mathrm{P}$
$\mathrm{C}$
$\mathrm{A}$

(11b) || Ken| wasted| little time| [[putting the addendum into action]].| (P66) 


\subsubsection{The $\mathrm{x}+\mathrm{g}$ Non-finite Verbal Group Clause as an Element of Group Structure}

The $122 \mathrm{x}+\mathrm{g}$ non-finite VBG clauses realising an element of group structure featured as PRG qualifier (89 or 73 percent), NMG qualifier (21 or 17 percent), and catenated VBG qualifier (12 or 10 percent). A set of NMGs with the $\mathrm{x}+\mathrm{g}$ non-finite $\mathrm{VBG}$ clause as qualifier is analysed as (12).

$\begin{array}{ll}\mathrm{M} & \mathrm{H} \\ \mid \mathrm{a} & \text { book } \\ \text { the } & \text { tension } \\ \text { the unhappy } & \text { children } \\ \text { the international } & \text { community }\end{array}$

\section{Q}

[[explaining the use of the compass]]| (L3)

[[arising from this situation]]| (M18)

[[wailing 'I want my mommy']]| (N20)

[[acting with compassion]]| (L66)

Two more are illustrated in context below. Notice embedding in (13a).

(13a) || Galileo| commissioned| an emblem representing Jupiter sitting on a cloud with the four stars circling about $\operatorname{him} . .(\mathrm{L} 4)$

(13b) ||There | is |silence | on,| for example,| the amount of retardation found in an English sample of children going to childminders. (N20)

Like (13b), the NMG diagrammed as (15) is qualifier in a PRG whose "missing" headword recoverable from context is for, as (14) below shows.

(14) || The same |goes |for the Bermuda studies |and |(for) other work [[revealing greater anti-social behaviour]].|| (N20)

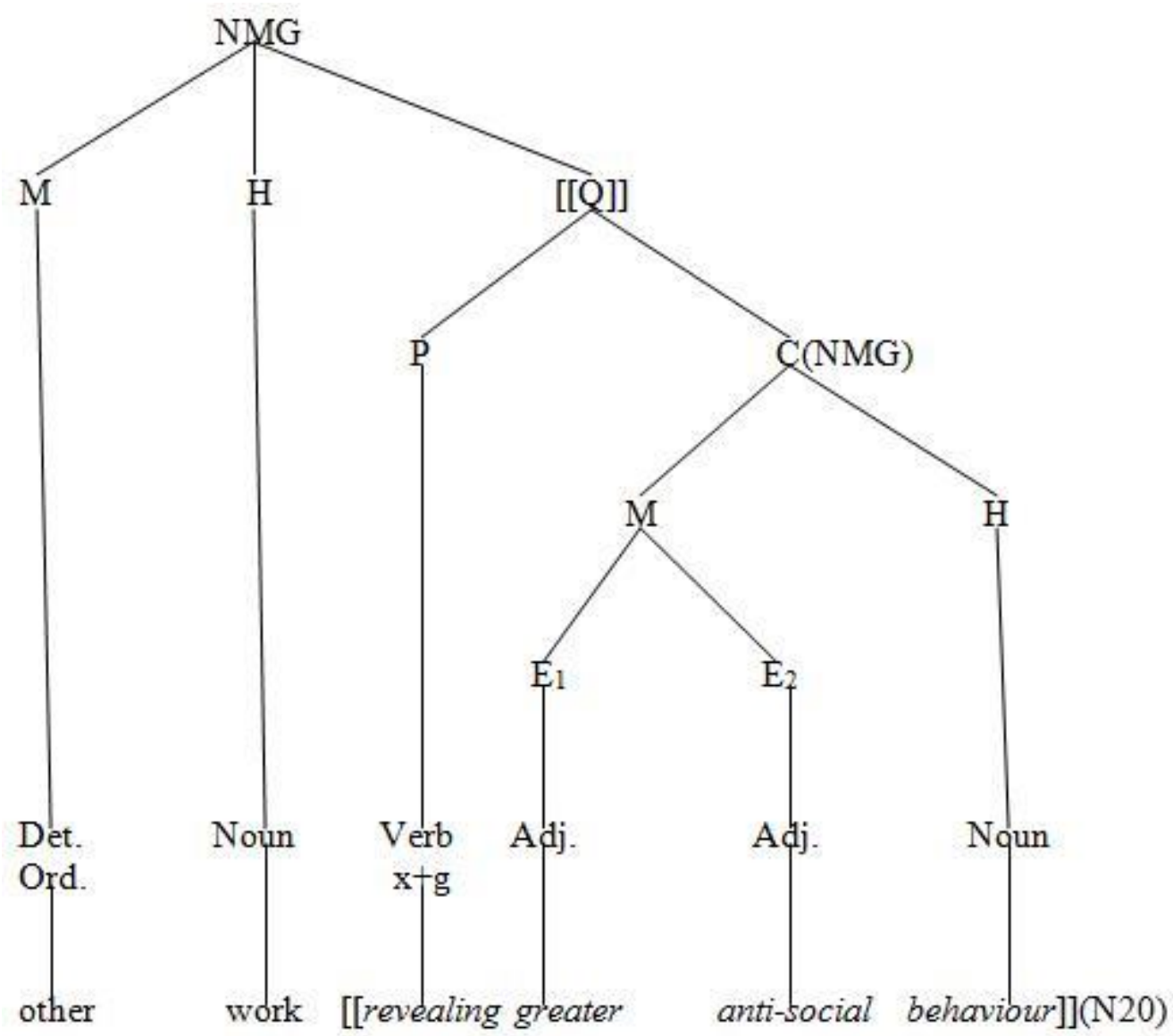

The $\mathrm{x}+\mathrm{g}$ non-finite VBG clause's dominance was due to its function as PRG qualifier. That no other form occurred in that position confirms Greenbaum's (1996) assertion in that regard. It also confirms the extreme rarity of $\mathrm{x}+\mathrm{O}$ as PRG qualifier. Here is a list of analysed examples. 
(16)

\begin{tabular}{|c|c|}
\hline $\mathrm{H}$ & Q \\
\hline out of & {$[[$ making do with the tools life handed them $]] \mid$ (B11) } \\
\hline by & {$[[$ taking alms $]] \mid(\mathrm{B} 12)$} \\
\hline by & {$[[$ being yourself $]] \mid(\mathrm{L} 5)$} \\
\hline bout & {$[[$ upsetting every person you come across $]] \mid$ (L7) } \\
\hline efore & {$[[$ commencing to trade $]] \mid$ (M18) } \\
\hline in & [[setting the affairs of Itsekiriland]]| (M25) \\
\hline & [[personally insulting childcare staff]]| (N18) \\
\hline & {$[[$ drawing attention to... $]] \mid(\mathrm{N} 20)$} \\
\hline & {$[[$ submitting a list of necessary...] $] \mid(\mathrm{P} 60)$} \\
\hline om & {$[[$ choosing him to be president $]] \mid$ (P64) } \\
\hline
\end{tabular}

One is analysed diagrammatically thus:

(17)

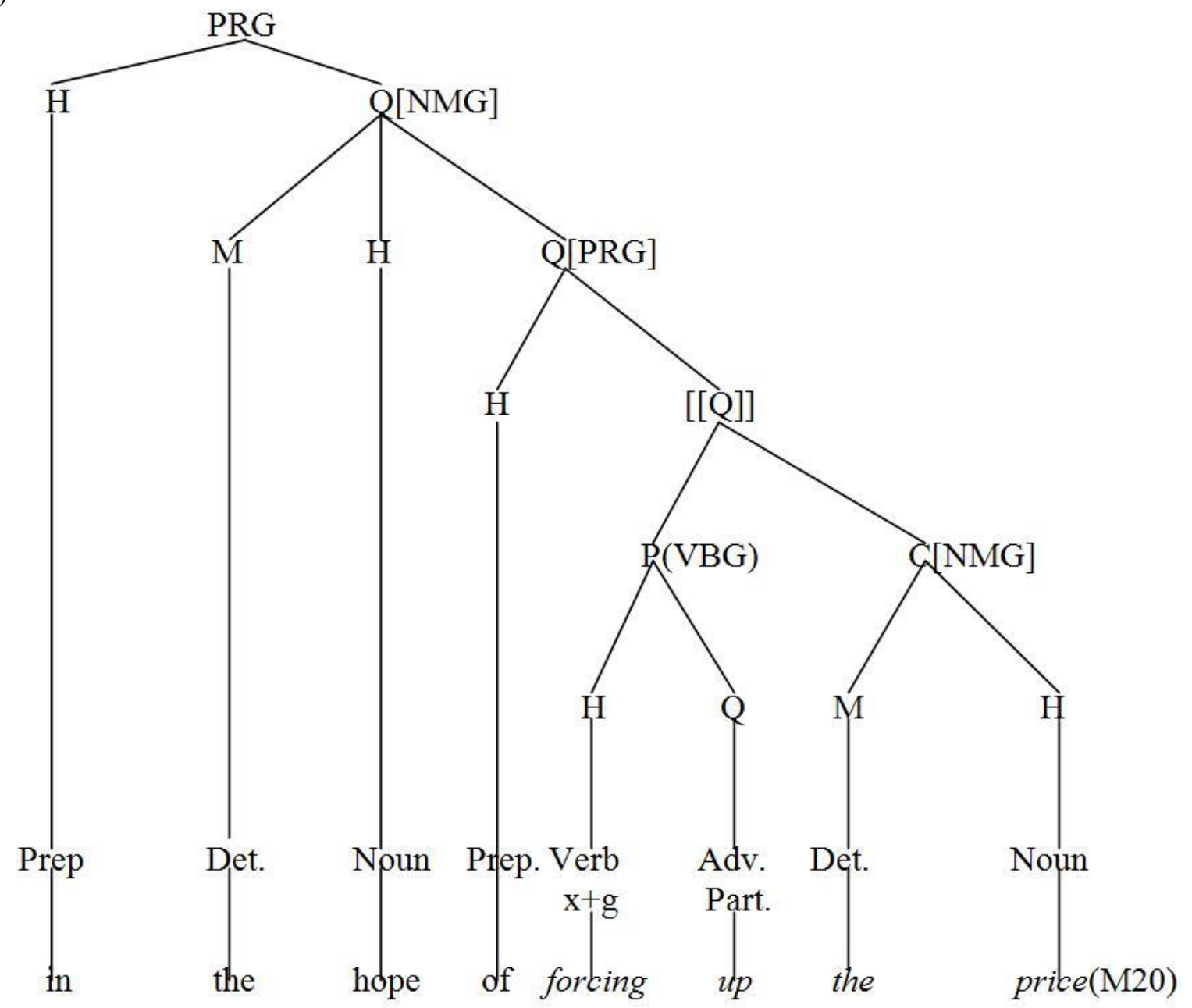

More PRGs with the $\mathrm{x}+\mathrm{g}$ non-finite VBG clause as qualifier are illustrated in context as follows.

(18a) || They |know labout [[ performing an appearance]].|| (B9)

(18b) || Galileo |gave |the Medicis| infinitely more glory |by [[ linking their name with cosmic forces| than| he had |by [[ making them the patrons of some new scientific gadgets or discovery]].||(L4)

(18c) ||Thereafter| no other efforts| were recorded| as[[ having been made to elect an Olu]].|| (M16) 
(18d) || ( $\beta$ ) As| even| specialists who did not question his findings |criticised | him | for [[ publishing them]]...|| (N20) (18e) || Ken | dissuaded |the committee| from [[choosing him to be president]].|| (P64)

Apart from being the qualifier of complex prepositions like out of and instead of, the $\mathrm{x}+\mathrm{g}$ non-finite VBG clause featured at the most delicate syntactic level, introducing further complexity through layers of group subordination as (17) shows. The PRG qualifiers did not all exhibit elaborate structures, however; some, like by [[being yourself]]|(L5), were manifestly simple.

\subsection{The $x+n$ Non-finite Verbal Group Clause}

The distribution of the $119 \mathrm{x}+\mathrm{n}$ non-finite VBG clauses as an element of sentence, clause and group structure was 26, 19 and 74 respectively. Each functional category is examined separately.

\subsubsection{The $\mathrm{x}+\mathrm{n}$ Non-finite Verbal Group Clause as an Element of Sentence Structure}

The $26 \mathrm{x}+\mathrm{n}$ non-finite VBG clauses realising an element of sentence structure as beta clause represent 22 percent of $\mathrm{x}+\mathrm{n}$ occurrence. They occurred at initial and end positions.

(19a) $\| \mid(\beta)$ Backed by Iye, $\|(\alpha)$ they were determined that no other prince of Akengbuwa or any other eligible candidate should occupy the throne.||| (M8)

(19b) $\|(\alpha)$ The Ogoni are faced by a powerful combination of titanic forces from far and near, $\|$

( $\beta$ ) driven by greed and cold statistics. ||$(\mathrm{P} 66)$

Dual manifestation in a single sentence was seen.

(20a) || ( $\beta$ ) Bent with age $\|(\alpha)$ the woman stood there every morning, $\|(\beta)$ her hands out-

stretched, $\|$ and $\|(\beta)$ her wizened skin enduring the harsh reprimand of the daily weather.|\| (B12)

(20b) $\| \mid(\beta)$ Reassured by the childcare lobby, $\|$ and $\|(\beta)$ bombarded with all the talk about educational and social gains for children raised in groups $\|:(\alpha)$ many parents are not aware of the ambivalences and caveats of some experts.||| (N22)

Disruption of the structural continuity of the alpha clause was also recorded.

(21a) || $\mid(\alpha-)$ Sometimes the Itsekiri traders, $\|(\beta)$ offended by the non-fulfilment of promises made by their Urhobo customers, $\|(-\alpha)$ sent their slaves...to raid the villages concerned.||| (M7)

(21b) || ( $\alpha-)$ Whether or not childcare is actually better, or, at least, harmless, for children, $\|$

$\|(\beta)$ compared to parental care, $\|(-\alpha)$ is an unpopular question to ask. $\| \mid(\mathrm{N} 18)$

4.3.2 The $\mathrm{x}+\mathrm{n}$ Non-finite Verbal Group Clause as an Element of Clause Structure

Nineteen $\mathrm{x}+\mathrm{n}$ non-finite VBG clauses representing 16 percent of its total occurrence realised an element of clause structure as subject ( 1 or 5.3 percent), complement ( 2 or 11 percent), and adjunct ( 16 or 84 percent) as indicated in brackets. Its single occurrence as subject and one of complement are as illustrated below.
$\mathrm{S}$
$\mathrm{P}$
$\mathrm{C}$

(22) || [[Added to internal difficulty]] |was |the problem of dealing with the white traders. || (M25)
A
$\mathrm{S} \quad \mathrm{P}$
$\mathrm{C}$

(23) || In a note to the naval authorities,| he | requested | [[that a gunboat be sent to the Benin River to mete out condign punishment]]. $\|$ (M15)

The $\mathrm{x}+\mathrm{n}$ non-finite VBG clause as adjunct featured with, or, without, a subject.
$\mathrm{A}_{1}$
$\mathrm{S}$
$P$
$\mathrm{A}_{2}$
$\mathrm{A}_{3}$

(24a) || A year after that,| his body |was fished out |of River Tiber, |a stone [[tied around his neck ]].|| (L5)
$\mathrm{S}$
$\mathrm{P}$
$\mathrm{C}+$
$\mathrm{P} \quad \mathrm{C}$
A +
$\mathrm{A}_{1}$ 
(24b) || Mr Henry| seized |him || and || kept| him| in confinement||and\| according to the general

$$
\begin{array}{lllllll}
\mathrm{S} & \mathrm{P}- & \mathrm{A} & -\mathrm{P} & \mathrm{P} & \mathrm{C} & \mathrm{A}
\end{array}
$$

report in the river,\| (which |is |however |denied), || kept | him | [[chained by the neck]].||

(M21)

There was coordination of $\mathrm{x}+\mathrm{n}$ non-finite VBG clauses as adjuncts too.

$\begin{array}{lllllllll}\mathrm{A}_{1} & \mathrm{~A}_{2} & \mathrm{~S} & \mathrm{P} & \mathrm{C} & \mathrm{A}_{3} & + & \mathrm{A}_{4}\end{array}$

(25) || Yet| in $1591 \mid$ Hideyoshi | had | him|| [[arrested]] and [[sentenced to death]].|| (L5)

4.3.3 The $x+n$ Non-finite Verbal Group Clause as an Element of Group Structure

Seventy-four (62 percent) $\mathrm{x}+\mathrm{n}$ non-finite VBG clauses realised an element of group structure as NMG qualifier (70 or 95 percent), catenated VBG qualifier ( 3 or 4 percent), and AJG qualifier (1 or 1.4 percent). Its single manifestation as AJG qualifier is presented first.
$\mathrm{M}$
$\mathrm{H}$
|more
important
$\mathrm{Q}$
[[than the work produced in his name]]|(L4)

Sixty-one percent (43) of the $\mathrm{x}+\mathrm{n}$ non-finite VBG clause in NMG qualifier function was at the primary degree of delicacy, 23 percent (16) featured at the secondary degree of delicacy, and 16 percent (11) functioned at the tertiary degree of delicacy. Each subset is exemplified below.

(27a) Primary degree

$\begin{array}{lll}\mathrm{M} & \mathrm{H} & \mathrm{Q} \\ & \mid \text { those } & {[[\text { indebted to the firm }]] \mid(\mathrm{M} 13)} \\ \mid \text { any } & \text { money } & {[[\text { liberated from the treasury }]] \mid(\mathrm{L} 2)} \\ \mid \text { the } & \text { damage } & {[[\text { done by the government }]] \mid(\mathrm{P} 63)} \\ \mid \text { the } & \text { gunboat } & {[\text { requested }] \mid(\mathrm{M} 15)} \\ \mid \text { a strident } & \text { piece } & {[[\text { entitled "The Coming War in the Delta" }]] \mid(\mathrm{P} 62)} \\ \mid \mathrm{a} & \text { nurse } & {[[\text { named Zor }]] \mid(\mathrm{P} 61)}\end{array}$

(27b) Secondary degree (within NMGs as Qs in PRGs)

M $\quad \mathrm{H} \quad \mathrm{Q}$

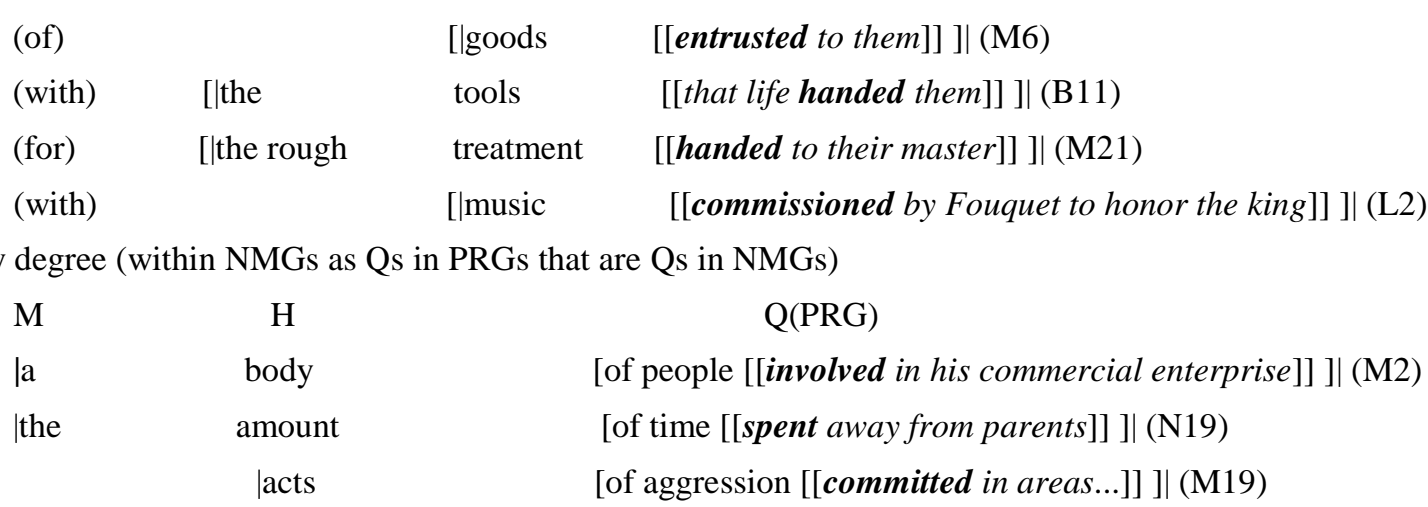

More $\mathrm{x}+\mathrm{n}$-as-qualifier NMGs at the primary, secondary and tertiary degrees of delicacy are illustrated in context as (28a)-(28c) respectively.

(28a) || The men concerned - white and black-| were | men [[schooled in the rough and tough days of the slave trade]]. $\|(\mathrm{M} 15)$

(28b) || And,| parents |are reassured |[[when daycare professionals talk in jargon and claim educational and social gains (for) children [[raised in groups]].\| (N22)

$(28 \mathrm{c}) \| \mid(\alpha)$ Childcare is no exception, $\|(\beta)$ given |the number and complexity of the factors involved. $\| \mid(\mathrm{N} 21)$ 


\subsection{The $x+o$ Non-finite Verbal Group Clause}

The $24 \mathrm{x}+\mathrm{o}$ non-finite VBG clauses occurred as an element of clause ( 21 or 88 percent) and group (3 or 13 percent) structure only. None realised an element of sentence structure and the group in question is the catenated VBG.

4.4.1The $\mathrm{x}+\mathrm{o}$ Non-finite Verbal Group Clause as an Element of Clause Structure

The $x+o$ non-finite VBG clause as an element of clause structure featured 17 times as adjunct and 4 times as complement, which respectively represent 71 and 17 percent of its proportion in the data. No evidence of its realisation as subject was seen.

The $x+o$ non-finite VBG clause as adjunct exhibited a variety of syntactic features: It occurred in imperative clauses and was also coordinated.

$$
\mathrm{P} \quad \mathrm{C}
$$

A

(29) || Make | him |[[appear more intelligent than you ]].||...

$\mathrm{P} \quad \mathrm{C}$

\section{A}

||Make| it |[[seem that you need his expertise]].|| (L6)
$\mathrm{A}_{1}$
$\mathrm{S}$
$\mathrm{C}$
$\mathrm{A}_{2}$
$+$
$\mathrm{A}_{3}$

(30) || By taking alms | she| helped| people | [[unload their guilt $]] \mid$ or| [[ facilitate their

$\mathrm{A}_{4}$

solicitations to the divine power ] | [[when they hand her their charity]].|| (B13)

As adjunct the $\mathrm{x}+\mathrm{O}$ non-finite VBG clause was almost always preceded by to-x+o.
$\ell \quad S$
C
$\mathrm{A}_{1}+$
$\mathrm{A}_{2}$

(31) ||| ( $\beta$ ) When| Ken | toured |Ogoniland |[[to present]]|and| [[explain this new document to the people ]],|| ( $\alpha)$ the Bill of Rights generated intense excitement.||| (P64)

Its capacity to realise multiple adjuncts in the same context is exemplified as follows.
$\mathrm{S}$
$\mathrm{P}$
C
A

(32) || Galileo |did not challenge| the intellectual authority of the Medicis| with his discovery,
$+\mathrm{P} \quad \mathrm{C}$
A
$\mathrm{A}_{1}$

$\|$ or $\|$ make | them |[[feel inferior in any way]]; || by literally aligning them with the stars,
$\mathrm{S} \quad \mathrm{P} \quad \mathrm{C}$
$\mathrm{A}_{2}$
$\mathrm{S}$
$\mathrm{P}$

| he |made | them |[[shine brilliantly among the courts of Italy]].||He| did not outshine |the
C S P
C
A

master, ||he | made |the master |[[outshine all others $]] . \|$ (L4)

Not only were the complements coordinated, $\mathrm{x}+\mathrm{o}$ also tended to follow $t o-\mathrm{x}+\mathrm{o}$ in a sequence of clausal coordination, as (33) and (34) respectively illustrate.
A
$\mathrm{S}$
$\mathrm{P}$
$\mathrm{C}_{1}$

(33) ||During such meetings, |the members, mostly older Ogoni elites,| preferred |to eat goat,|

$$
\mathrm{C}_{2}+\mathrm{C}_{3}
$$

|[[chew corn $]], \mid$ and |[[talk about girl friends]].|| (P64)

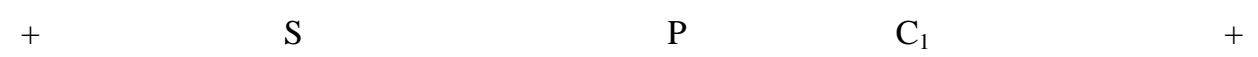

(34) ||And| their usual reaction to such a situation... |was|[[to send a protest to their consul]]| and

$\mathrm{C}_{2}$

|[[request his intervention with a view to the resumption of trade ]].|| (M20)

In the coordinated clauses $\mathrm{x}+\mathrm{o}$ behaved like an auxiliary in code function, suggesting that it is morphologically clipped from to-X+o, as to try and save (P62) further illustrates. This tendency was also exhibited (to a lesser degree, though) by $\mathrm{x}+\mathrm{n}$, e.g., needs to be qualified and amplified (M10). 


\subsection{The Non-finite Verbal Group as an Element of the Catenated Verbal Group Structure}

Table 3 above reveals that 110 non-finite VBGs representing 17.2 percent of the data realised an element of the catenated VBG structure as headword (6 or 6 percent) and as qualifier (104 or 95 percent). Each functional position is described below.

\subsubsection{The Non-finite Verbal Group as Catenated Verbal Group Headword}

Thirty-six catenative verbs served as headwords but only 8 (22 percent) headed catenated non-finite VBGs. Two are accounted for elsewhere while the 6 assignable to this position only are analysed as (35) below. Notice that all are morphologically $\mathrm{x}+\mathrm{g}$ and structurally $\mathrm{HQ}$.

\begin{tabular}{ll}
\multicolumn{1}{c}{$\mathrm{H}$} & \multicolumn{1}{c}{$\mathrm{Q}$} \\
|making & dol (B11) \\
|letting & outshine| (L6) \\
|hoping & [to bypass] (P60) \\
|commencing & [to trade] (M18) \\
|failing & [to agree] (M20) \\
|trying & [to maintain] (N21).
\end{tabular}

The only one realising an element of sentence structure is illustrated in context thus:

(36) || $\mid(\alpha)$ According to regulations, new clinics had to be registered with the state. ||

||| ( $\beta$ ) Hoping to bypass this expensive, time-consuming formality, ||( $\alpha$ ) Owens talked to a

friend who owned the Princess Medical Centre, a small private clinic in Port Harcourt.||

(P60)

\subsubsection{The Non-finite Verbal Group as Catenated Verbal Group Qualifier}

The to-X+o non-finite VBG was dominant as catenated VBG qualifier; it had 92 (90 percent) occurrences whereas $\mathrm{x}+\mathrm{g}(6), \mathrm{x}+\mathrm{n}(3)$, and $\mathrm{x}+\mathrm{o}$ (3) were low occurring as the enclosed figures indicate. Indeed 97 percent of to- $\mathrm{x}+\mathrm{o}$ as an element of group structure was as qualifier in the catenated VBG. Here is a list of analysed examples.

$\mathrm{M}$

|could not be

|had

|had

|might

|having
$\mathrm{H}$ |attempt

expected |needs |sought continued come expected |threaten |needs wish |ceases |seemed failed
Q

[to solve] (M9)

[to cooperate]| (M25)

[to be qualified]| (M4)

[to transfer]| (P59)

[to recognise]| (P66)

[to believe]| (L5)

[to be named]| (L2

[to sue]| (B10)

[to be seen] (B11)

[to hasten]| (N22)

[to be]| (N22)

[to have been involved]| (M3)

[to get] (M16) 
More are analysed diagrammatically below.

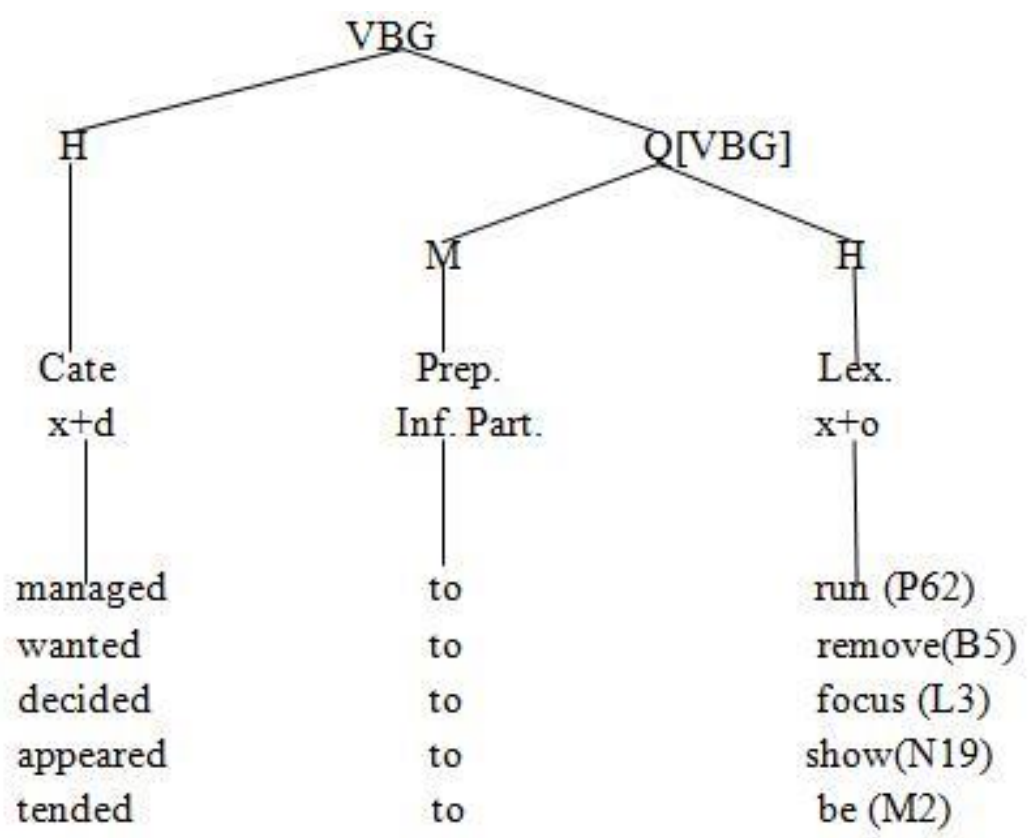

Tree diagram (39) shows that the $t o-\mathrm{X}+\mathrm{o}$ form at $\mathrm{Q}$ can be manifestly complex.

(39)

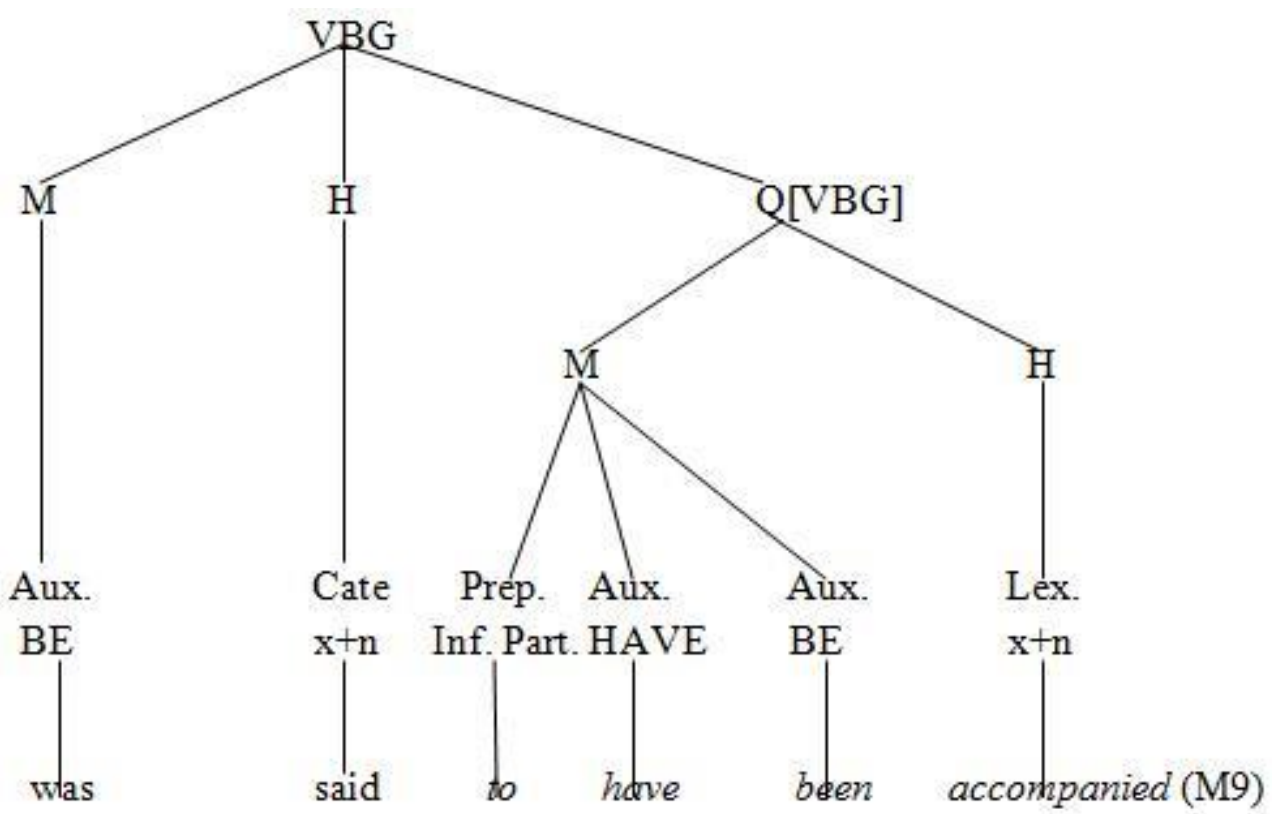

The following analysis further confirm that the form is part of the predicator element and does not initiate a to- $\mathrm{x}+\mathrm{O}$ non-finite VBG clause as complement or adjunct.
$\ell$
$\mathrm{S}$
$\mathrm{P}$
A

(40a)...|| [[before| the Europeans| were allowed to trade $\mid$ in the Olu's territory]].|| (M16)

$\begin{array}{llll}\ell & \mathrm{P} & \mathrm{A}\end{array}$

(40b) || ( $\beta$ ) When| beggars $\mid$ threaten to sue| the state| for [[obstructing their means of livelihood]], || (B10) 
S

$\mathrm{P}$

$\mathrm{C}$

(40c) || All masters |want to appear |more brilliant than other people.|| (L4)

Unlike in (40a) where it is the catenative verb headword with to trade as Q, allow in (41) below is the lexical verb headword of the MH-Type VBG at P. To evaluate (after the intervening nominal them at C) is not concatenated with allow; rather, it independently realises the P of its own non-finite VBG clause at A.

$\mathrm{S} \quad \mathrm{P}$

$\mathrm{C}$

A

(41)...|that| would allow |them| [[ to evaluate the quality of the childcare their children are receiving or might receive]].\| (N22)

Note that while an intervening nominal may suggest non-concatenation, its absence is not always indicative of concatenation. This feature is amply illustrated by $\|(\boldsymbol{\beta})$ waiting | to be fed $\|$, a rankshifted $\mathrm{x}+\mathrm{g}$ non-finite VBG clause at $\mathrm{A}_{4}$ in (11a) above, whose structure is $\|\mathrm{P} \mid \mathrm{A}\|$.

The catenated VBGs with $\mathrm{x}+\mathrm{g}$ as qualifier are cannot help being (L5), had stopped paying (M21), started accepting (P60) and began sending (P65). Another is shown in context as (42) while the only catenated to-x+o non-finite VBG is diagrammed as (43) below.

(42) ||| ( $\beta$ ) To further upset matters, $\|(\alpha)$ Ken |began promoting |the idea that MOSOP should create community subgroups, $\|(\beta)$ following the model of South Africa.||| (P65)

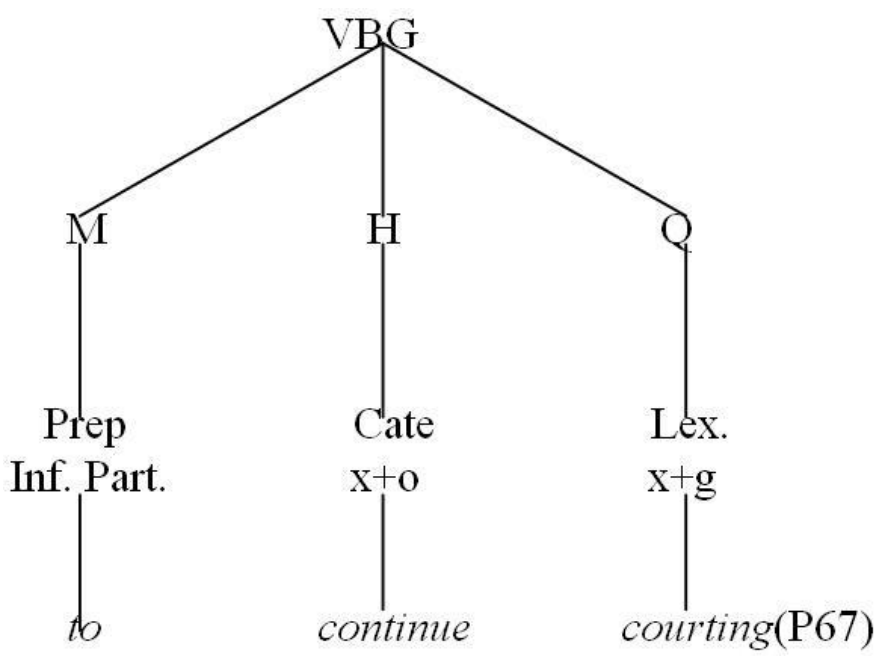

All three $\mathrm{x}+\mathrm{n}$ non-finite form qualifiers occurred with the GET catenative: do get stuck (B11), get fed (N19) and get sent $(\mathrm{N} 23)$. The last is shown in context below.

(44) || Children who get sent to nurseries |may be |more developmentally advanced,| healthier, and |resilient than those who stay at home, $\| . .(\mathrm{N} 23)$

The $\mathrm{x}+\mathrm{o}-\mathrm{as}-q u a l i f i e r$ non-finite VBGs are making do (B11), let get (L5), and letting outshine (L6), shown in context as (45).

(45) ||In all of these cases it is not a weakness to disguise our strengths if in the end they lead to power. $\|$ By[[letting others outshine you]], || you | remain |in control,| instead of being a victim of their insecurity.|| (L6)

This ends the analysis of data. Summary and discussion of findings now follow.

\section{Summary and Discussion of Findings}

From the analysis undertaken and the observations made the following points would seem relevant concerning the non-finite VBG clause vis-à-vis the three problems identified and the research questions raised in the introductory section of this paper.

Starting with frequency of occurrence and related issues of function, the analysis has confirmed the syntactic functions associated with the non-finite VBG clause, empirically determined its frequency of occurrence in the corpus generally and in the syntactic positions particularly, and revealed that its frequency varies significantly according to texts and according to functions. The non-finite VBG clause featured 36 times in 1000 words and was 
most frequent in Text B and least frequent in Text $\mathrm{N}$, occurring 46.3 and 31.7 times in 1000 words respectively. Text $\mathrm{L}$ recorded 41.8, Text P 41.13, and Text M 31.8, occurrences in 1000 words. The non-finite VBG clause was far more prominent as an element of group (46 percent) and clause (40 percent) structure than as an element of sentence structure (14 percent). Its most prominent syntactic position was adjunct, where its 35 percent realisation was about $2^{1 / 2}$ times more than its function as beta clause, NMG qualifier and PRG qualifier, which respectively represent 14, 15, and 14, percent. While its realisation as catenated VBG headword was 0.93 percent and qualifier 16.2 percent, the non-finite VBG clause's percentage proportion as AJG qualifier, subject, and complement was 0.16, 0.31 , and 5 respectively. No evidence of ADG qualifier was seen. The absence of studies encompassing all four morphological variants makes comparison difficult: It cannot be said, for instance, that the rates recorded here are high or low.

The analysis has confirmed $\mathrm{x}+\mathrm{o}, t o-\mathrm{x}+\mathrm{o}, \mathrm{x}+\mathrm{g}$ and $\mathrm{x}+\mathrm{n}$ as the morphological variants of the English non-finite VBG clause and provided empirical facts in support of existing claims about their relative numerical superiority or inferiority. Furthermore, it has determined the proportion of each form in the corpus and in the different texts as well as in the various syntactic positions. Beginning with the to-x+o non-finite VBG clause, results show that it was the highest occurring with 46 percent representation of the data. It had a frequency of 17 in 1000 words and was most frequent in Text P (21.4 in 1000$)$ and least frequent in Text $\mathrm{N}$ (13.3 in 1 000). These figures far exceed the 50 in 1 000,000 (0.05 in 1 000) words De Smet (2007) reported in respect of for... to infinitive construction, the form closest to $t o-\mathrm{x}+\mathrm{o}$. The $t o-\mathrm{x}+\mathrm{o}$ non-finite $\mathrm{VBG}$ clause's dominant functional positions were adjunct and catenated VBG qualifier: It accounted for 77 percent and 90 percent of their total realisation and they each represent 59.3 percent and 31 percent of its total occurrence respectively. In contrast, its realisation as complement, NMG qualifier, and beta clause was only 5,1, and 4, percent respectively. Egan's (2008) report that to-x+o collocates with limited range of predicators because over $2 / 3$ of randomly downloaded to-x+o constructions collocated with copular verbs may offer a syntactic explanation for the absence of subjects and paucity of complements realised by the $t o-\mathrm{x}+\mathrm{o}$ form. But there is also a significant textual and stylistic dimension: Whereas the source text for the often cited example "To err is human, to forgive, divine" is poetry, precisely Alexander Pope (cf. Jespersen 1933), the texts analysed are factual narratives devoid of fictionalisation of both form and situation.

The $\mathrm{x}+\mathrm{g}$ non-finite VBG clause ranked second with its 32 percent representation of the data and 11.3 in 1000 word-occurrence, which was highest in Text L (18.3 in 1 000) and lowest in Text M (8.4 in 1 000). Significantly 44 percent of $x+g$ occurrence was as PRG qualifier (It alone realised that function) and 26 percent was as beta clause (This constitutes 59 percent of that position's total realisation). The $\mathrm{x}+\mathrm{g}$ was however low occurring as NMG qualifier, adjunct and complement, and was evidently rare as subject, as the percentage representations of 10, 9.3, 4, and 0.5 respectively show. The third was $\mathrm{x}+\mathrm{n}$ non-finite $\mathrm{VBG}$ clause with a proportion of 19 percent and a frequency of 7 in 1000 words, which was most frequent in Text B (10.2 in 1000$)$ and least frequent in Text P (4.4 in 1000$)$. It was the dominant form in NMG qualifier function, with 75 percent realisation representing 59.3 percent of its total occurrence. Though relatively high occurring as beta clause (22 percent), the $x+n$ non-finite VBG clause was extremely rare as subject ( 0.9 percent) and complement ( 1.7 percent). The least frequently used non-finite VBG clause was $x+o$. It represents 4 percent of the data, occurred 1.33 times in 1000 words, and was highest in Text $\mathrm{L}$ (4.9 in 1000$)$ and lowest in Text M (0.12 in 1000$)$. Although it accounted for only 7 percent of adjuncts, that position actually represents 71 percent of its total occurrence. The $\mathrm{x}+\mathrm{o}$ form never featured as PRG qualifier and was quite low occurring as complement (17 percent) and catenated VBG qualifier (13 percent). This analysis has thus confirmed $t o-\mathrm{x}+\mathrm{O}$ and $\mathrm{x}+\mathrm{g}$ as the most recurring forms, $\mathrm{x}+\mathrm{n}$ as low occurring, and $\mathrm{x}+\mathrm{O}$ as highly "restricted".

The syntactic status of the non-finite form immediately after the catenative verb has been confirmed as qualifier. The analysis has further demonstrated that the non-finite VBG constitutes a syntactic whole with the preceding catenative and does not function as complement or adjunct. Using $\|$ waiting | to be fed $\|$, among others, it has also demonstrated that the absence of an intervening nominal does not necessarily indicate concatenation of the to- $\mathrm{x}+\mathrm{O}$ non-finite VBG with the preceding verb lexeme. The existing confusion and descriptive inaccuracy are due to the Janus-faced property of the catenative, which makes it belong also to the lexical subclass of the verb lexeme. Furthermore, the analysis has empirically established the to-x+o non-finite VBG as the dominant qualifier in the catenated VBG structure: It accounted for 89 percent whereas the $x+g, x+o$ and $x+n$ forms represent 6,3 , and 3 percent respectively. These figures fairly correspond with Duffley's (2004) 93 v 7 report on to-x+o and $x+g$ with like and Deshors' (2015) 86 v 14 finding on the same forms as verb complements generally. This interpretation would seem to hold were the variables examined $t o-x+o$ and $x+g$ only, which would give percentage proportions of 94 and 6 respectively. The fluidity of $t o-\mathrm{x}+\mathrm{o}$ and $\mathrm{x}+\mathrm{g}$ with a variety of catenatives (help, continue, start, and begin only) and the restriction of $x+o$ and $x+n$ (cf. Huddleston,1984) were thus confirmed. 
In the course of addressing the issues raised in this study not a few insights were gained into the structure of the three grammatical units (sentence, clause and group) within which the non-finite VBG clause operates as an element of structure. One on each will suffice. Ordinarily when the dependent clause (finite or non-finite) combines with the independent clause, the resulting sentence is described as syntactically complex because both clauses are of unequal grammatical status. This analysis has shown that dependent $x+g$ and $x+n$ non-finite VBG clauses commonly disrupt the structural continuity of the independent finite VBG clause in natural language, resulting in further syntactic complexity. No evidence of $t o-x+o$ and $x+o$ was seen. Coordination of complements and adjuncts realised by the non-finite VBG clause was common, and the non-finite VBG clause also served as complements and adjuncts of clauses marked for imperative mood. Not only was the non-finite VBG clause as qualifier structurally complex, involving chains of group or clausal subordination or both, it functioned at the most delicate level syntactically, as the significant 39 percent $x+n$ NMG qualifier attests. Above all, this paper has shown that there are gains derivable from studying the non-finite VBG clause as a syntactic occurrence, which cannot be glimpsed from a solely semantic approach restricted to two morphological variants and one syntactic function (complement).

\section{Conclusion}

Explanations for the significant differences in the frequency of occurrence and distribution of the non-finite VBG clause and its morphological variants can now be offered as concluding remarks. The authors' individualism (style preference), theses variation, and features inherent in the non-finite VBG clause as a grammatical entity account for many of the issues that there are in the texts analysed and combine to determine how frequently the non-finite VBG clause was selected in each text. These factors equally explain what happens in everyday natural language use. Even when a language user recognises a particular grammatical form, its frequency of use is often constrained by a combination of factors such as those implicated in this study. Two instances in the texts analysed will suffice: One is the high frequency of the inherently abstract $\mathrm{x}+\mathrm{g}$ non-finite VBG clause in sections of Text $\mathrm{N}$ describing the psychological state of children kept in daycare. Another is the tendency of $x+o$ to almost invariably follow to- $x+o$ in a sequence of clausal coordination that suggests it is contextually a morphological remnant of the latter, with its infinitival particle to clipped. These could not have been coincidental. Deliberate choices must have been made in order to actualise the authors' set objectives and these border on theses, style preference, and formal properties of the grammatical entity in question. So variations inevitably occur in the form of language used in texts. What is paramount, as this study has revealed, is for a true picture of the grammatical form to ultimately emerge at the end of the analysis. If the current study has exposed that much concerning the English non-finite VBG and its clause, then its goals would have been met and this should be consolidated through further text-based research.

\section{References}

Adejare, R. A. \& Adejare, O. (2006). Tertiary English Grammar (2nd edn.). Lagos: DIFAMO Books.

Adejare, R. A. (2013). The English Verbal Group: Its Form, Meaning and Function. Saarbrücken: LAP LAMBERT Academic Publishing.

Adelakun, A. (2015). El-Rufai and his Beggars. The Punch. Thursday, 16 July 2015, p62. (Text B)

Alexiadou, A. (2013). Nominal vs. Verbal -ing Constructions and the Development of the English Progressive. English Linguistics Research, 2(2) 126-140. http://dx.doi.org/10.5430/elr.v2n2,p126-140

Berry, M. (1975). Introduction to Systemic Linguistics I: Structure and Systems. London: B. T. Batsford.

De Smet, H. (2007). For ... to-infinitives as Verbal Complements in Late Modern and Present-day English: Between Motivation and Change. English Studies, 88(1), 67-94. http://dx.doi.org/10.1080/ 00138380601042766

Deshors, S.C. (2015). A Multifactorial Approach to Gerundial and to-infinitival Verb-Complementation Patterns in Native and Non-native English. English Text Construction, 8(2), 207-235. http://dx.doi.org/10:1075/etc.8.2.04des

Downing, A. \& Locke, P. (2002). A University Course in English Grammar. London: Routledge.

Duffley, P. J. (2004). Verbs of Liking with the Infinitive and the Gerund. English Studies, 85(4), 358-380. http://dx.doi.org/10.1080/00138380412339185

Duffley, P.J. \& Tremblay, R. (1994). The Infinitive and the -ing as Complements of Verbs of Effort. English Studies, 75(6), 566-575. http://dx.doi.org/10.1080/00138389408598945

Egan, T. (2008). Non-finite Complementation: A Usage-based Study of Infinitive and -ing Clauses in English. Amsterdam: Rodopi. http://dx.doi.org/10.1163/9789401205542 
Eggins, S. (2004). An Introduction to Functional Linguistics (2nd edn.). London: Continuum.

Farego, T. (1997). On Pattern of Complementation with Verbs of Effort. English Studies, 78(1), 60-67. http://dx.doi.org/10.1080/0013838989708599061

Farrokh, P. \& Mahmoodzadeh, K. (2012). English Nominal Clauses: Analyzing the Translation of Subordinate wh-clauses in Azeri. English Linguistics Research, 1(1), 137-144. http://dx.doi.org/10.5430/elr.v1n1p137

Green, R. (1998). The 48 Laws of Power. London: Penguin Books (Chapter1: Never Outshine the Master,p1-7).(Text L)

Greenbaum, S. \& Nelson, G. (2002). An Introduction to English Grammar (2nd edn.). London: Longman.

Greenbaum, S. (1996). The Oxford English Grammar (2nd edn.). Oxford: Oxford University Press.

Halliday, M.A.K. (1961). Categories of the Theory of Grammar. Word, 17(3), $241-292$. http://dx.doi.org/10.1080/00437956.1961.11659756

Huddleston, R. (1984). Introduction to the Grammar of English. Cambridge: Cambridge University Press. http://dx.doi.org/10.1017/CBO9781139165785

Hunt, J. T. (2005). The Politics of Bones. Toronto: McClelland and Stewart (Chapter3: p59-67). (Text P)

Ihalainen, O. (2004). A Point of Verb Syntax in South-Western British English: An Analysis of a Dialect Continuum. In G. Sampson \& D. McCarthy (Eds.), Corpus Linguistics: Readings in a Widening Discipline. London: Continuum, p113-121.

Ikime, O. (1995). Merchant Prince of the Niger Delta. Special Centenary Edition. Ibadan: Ikime, O. (Chapter1: Introduction: Trade and Politics in Itsekiriland, 1850-84,p1-26). (Originally published by Heinemann Educational Books Ltd, London, 1968). (Text M)

Jespersen, O. (1933). Essentials of English Grammar. London: George Allen \& Unwin Ltd.

Kolln, M. \& Funk, R. (2010). Understanding English Grammar (2nd edn.). New York: Longman.

Morgan, P. (1996). Who Needs Parents?: The Effects of Childcare and Early Education on Children in Britain and the USA. London: The IEA Health and Welfare Unit (Chapter1: What the Research Tells us,p18-23). (Text N)

Palmer, F. R. (1987). The English Verb (2nd edn.). London: Longman.

Quirk, R., Greenbaum, S., Leech, G. \& Svartvik, J. (1985). A Comprehensive Grammar of the English Language. London: Longman.

Radford, A. (2004). English Syntax: An Introduction. Cambridge: Cambridge University Press. http://dx.doi.org/10.1017/CBO9780511841675

Rodhenberg, G. (1995). On the Replacement of Finite Complement Clauses by Infinitives in English. English Studies, 76(4), 367-388. http://dx.doi.org/10.1080/00138389508598980

Rudanko, J. (1998). To infinitive and to-ing Complements: A Look at some Matrix Verbs in Late Modern English and Later. English Studies, 79(4), 336-348. http://dx.doi.org/10.1080/0013838908599138

Scott, F.S., Bowley, C.C., Brockett, C.S., Brown, J.G. \& Goddard, P.R. (1968). English Grammar :A Linguistic Study of its Classes and Structure. London: Heinemann Educational Books Ltd.

Strang, B. M.H. (1969). Modern English Structure. London: Edward Arnold.

Taher, I. I. (2015). The Problematic Forms of Nominalization in English: Gerund, Verbal Noun, and Deverbal Noun. English Linguistics Research, 4(1), 30-40. http://dx.doi.org/10.5430/elr.v4n1p30 